\title{
Properties of Surfactin C-15 Nanopeptide and Its Cytotoxic Effect on Human Cervix Cancer (HeLa) Cell Line
}

\author{
Zahra Nozhat, Asadollah Asadi, and Saber Zahri \\ Deptartement of Biology, Faculty of Science, University of Mohaghegh Ardabili, Ardabil 11367-56199, Iran \\ Correspondence should be addressed to Asadollah Asadi, asad.asady@gmail.com
}

Received 16 February 2012; Revised 24 October 2012; Accepted 9 November 2012

Academic Editor: Xiaoming Li

Copyright () 2012 Zahra Nozhat et al. This is an open access article distributed under the Creative Commons Attribution License, which permits unrestricted use, distribution, and reproduction in any medium, provided the original work is properly cited.

Surfactin is one of the most powerful biosurfactants that has been known so far. It is an acidic cyclic nonribosomal lipoheptapeptide that is produced by Bacillus subtilis. In this presentation we investigated different properties of surfactin C-15. The nanomicelle forming ability of surfactin C-15 in different aqueous environments with various ionic strengths was studied by scanning electron microscope. Surfactin second structure was investigated by Far-UV CD spectrum. Its hemolytic activity and cytotoxicity were measured by hemolysis and MTT assays, respectively. Surfactin formed spherical nanomicelles in distilled water $(\mathrm{pH}=7.4)$ and amorphous nanomicelles in PBS buffer $(\mathrm{pH}=7.4)$. The hemolysis assay results indicated that $\mathrm{HC}_{50}$ of surfactin was $47 \mu \mathrm{M}$. Surfactin C-15 arrested growth of human cervix cancer HeLa cell line in a time- and dosage-dependent method, so that its $\mathrm{IC}_{50}$ at 16,24 , and $48 \mathrm{~h}$ were $86.9,73.1$, and $50.2 \mu \mathrm{M}$, respectively.

\section{Introduction}

Surfactin-like lipopeptides produced by the genus Bacillus are one of the most important classes of these natural compounds. They have low critical micelle concentration (CMC), stable emulsification properties, and excellent foamability [1]. Surfactin is an efficient biosurfactant produced by some Bacillus subtilis strains. It is a cyclic lipoheptapeptide containing seven amino acids and a $\beta$-hydroxyl fatty acid. In aqueous solution the peptide ring of surfactin shows a "horse-saddle" topology because of the two negatively charged amino acid residues l-Glu and l-Asp [2]. Due to its amphiphilic structure it shows unique surface-, interface-, and membrane-active properties [3]. It also has hemolytic, anticoagulant, antimicrobial and antitumoral activities [1, 46] inhibition of cAMP phosphodiesterase [7], and antiHIV properties $[7,8]$. These activities are related with their interactions with biomacromolecules such as enzymes and lipopolysaccharide. The surfactant properties and biological activities of surfactin analogues appear very interesting in the perspective of their utilization both in cosmetic and in pharmaceutical fields. Surfactins are a large variety of isoforms which differ by variation of the length and branching of their fatty acid components as well as by amino acid replacements in their peptide ring [1]. How this molecule can be effective in various biological events is still largely unknown; however, it is speculated that the structural and lipophilic properties of surfactin may affect the stability of biological membranes [9]. With attention to the increasing application of diverse biocompatible nanoparticles in medicine and considering that active fields of research are currently also dedicated to investigate the applications of biosurfactants in pharmaceutical and biomedical sciences and knowing that the surfactin is one of the most powerful biosurfactants [10-15], in this presentation, after investigation of different properties of surfactin C-15 such as its nanomicellization ability, secondary structure, and hemolytic activity, we studied its cytotoxic effect on HeLa cell line.

\section{Materials and Methods}

2.1. Materials. Surfactin and 3-(4,5-Dimethylthiazol-2-yl)2,5-diphenyl Tetrazolium Bromide (MTT) were obtained from Sigma. RPMI-1640, fetal bovine serum (FBS), and Trypsin-EDTA 5x were purchased from Gibco, and HeLa cell line was obtained from Pastor Institute of Iran.

2.2. Surfactin Second Structure Study. The Far-UV CD spectrum of surfactin was recorded in PBS $(\mathrm{pH}=7.4)$. It 


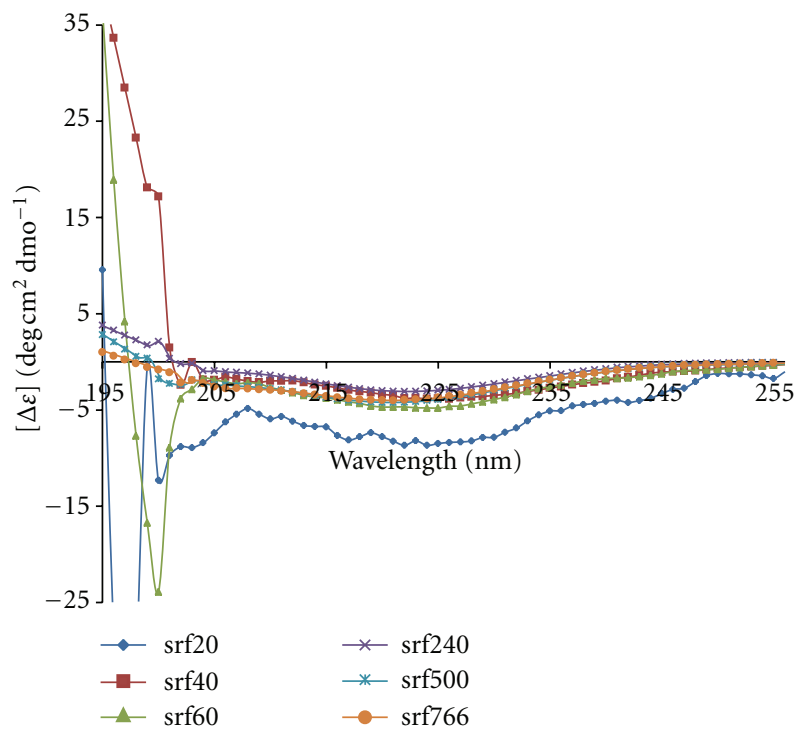

Figure 1: CD spectrum of surfactin in PBS.

was measured by AVIV 215 spectropolarimeter in different concentration $(20,40,60,240,500$, and $766 \mu \mathrm{M})$ at $25^{\circ} \mathrm{C}$. The wavelength ranged between 195 and $260 \mathrm{~nm}$.

2.3. Physical Characterization of Surfactin Nanomicelles. For the preparation of nanomicelles by surfactin, $1 \mathrm{mg}$ surfactin was sonicated in $1 \mathrm{~mL}$ distilled water $(\mathrm{pH}=7.4)$ and $1 \mathrm{~mL}$ PBS (phosphate buffer saline, $\mathrm{pH}=7.4$ ) for $15 \mathrm{~min}$ at $30^{\circ} \mathrm{C}$. The size and shape of nanomicelles were studied by scanning electron microscope (SEM, LEO1430VP).

2.4. Red Blood Cell Preparation. Human red blood cells (RBCs) were separated by centrifugation at $2000 \times$ g. RBCs were then washed once in PBS-EDTA and three times in an isotonic buffer $(10 \mathrm{mM}$ Tris, $150 \mathrm{mM} \mathrm{NaCl}$ adjusted to $\mathrm{pH}$ 8.5 with $\mathrm{HCl}$ ). RBCs were then suspended in this buffer at a cell density of $5 \times 10^{8}$ cells $/ \mathrm{mL}$ [16].

2.5. Hemolysis Assay. $850 \mu \mathrm{L}$ of isotonic buffer was added to $50 \mu \mathrm{L}$ of a PBS solution containing the copolymer. $100 \mu \mathrm{L}$ of $\mathrm{RBC}$ suspension was added, and the reaction was performed at $25^{\circ} \mathrm{C}$ during $30 \mathrm{~min}$. Unaltered $\mathrm{RBCs}$ were then removed by a $10000 \times \mathrm{g}$ centrifugation, and the absorbance of the supernatant at $540 \mathrm{~nm}$ was compared with two control samples in order to determine the percentage of hemolysis. The first one (100\%) was totally hemolysed with distilled water [16], and the second one (0\%) contained $900 \mu \mathrm{L}$ PBS plus $100 \mu \mathrm{L}$ of RBC suspension. Each test has been carried out at least twice.

2.6. Cell Culture. Human cervix cancer HeLa cell line was cultured in RPMI-1640 medium containing $10 \%$ fetal bovine serum, $100 \mathrm{U} / \mathrm{mL}$ penicillin, $100 \mathrm{U} / \mathrm{mL}$ streptomycin, and $1 \%$ glutamine in a humidified cell incubator with an atmosphere of $5 \% \mathrm{CO}_{2}$ at $37^{\circ} \mathrm{C}[17]$.

2.7. MTT Assay. Cell viability was estimated by MTT assay. Briefly, $3 \times 10^{6}$ cells/well was plated in 24 -well culture plates. After overnight incubation, the cells were treated with different concentrations of surfactin $(0,20,40,60$, and $80 \mu \mathrm{M})$ for 16,24 , and 48 hours. The cells were treated with $50 \mu \mathrm{L}$ of $5 \mathrm{mg} / \mathrm{mL}$ MTT and the resulting formazan crystals were dissolved in DMSO $(500 \mu \mathrm{L})$. The optical density (OD) of each well was measured at $570 \mathrm{~nm}$. Each test was performed in triplicate experiments. The effect of surfactin and surfactin-loaded nanoparticles on cell viability was assessed as percentage cell viability compared to vehicle-treated control cells, which were arbitrarily assigned $100 \%$ viability $[18,19]$.

2.8. Statistical Analysis. All of the experiments were done in triplicates, and the averages of the data were compared with independent $t$-test. A $P$ value of $<0.05$ was considered as a statistical significance.

\section{Results}

3.1. Surfactin Second Structure Study. Surfactin C-15 in PBS showed a CD spectrum dominated by a broad negative band centered at $225 \mathrm{~nm}$ and a maximum peak at $195 \mathrm{~nm}$ (Figure 1). Surfactin second structure percents were measured (Table 1).

3.2. Physical Characterization of Surfactin Nanomicelles. Micellization ability of surfactin C-15 was studied by scanning electron microscope. The results exhibited that the nanomicelles in distilled water were spherical in shape and their size was about 100-200 $\mathrm{nm}$ (Figure 2(a)), while the nanomicelles shape in PBS was amorphous and their size was 100-400 nm (Figure 2(b)).

3.3. Hemolysis Assay. Surfactin C-15 was tested in different concentration for its hemolytic activity. The results were exhibited in Figure 3. It gives rise to a concentrationdependent hemolysis [10]. $\mathrm{HC}_{50}$ which is defined as the 
TABLE 1: Surfactin second structure percents.

\begin{tabular}{|c|c|c|c|c|c|c|}
\hline Material & $\alpha$-helix & Antiparallel & Parallel & $\beta$-turn & Rndm.coil & Total sum \\
\hline Srf $20 \mu \mathrm{M}$ & 13.2 & 22.4 & 11.9 & 16.8 & 35.7 & 100 \\
\hline Srf $40 \mu \mathrm{M}$ & 10.8 & 22.7 & 12.7 & 16.1 & 37.7 & 100 \\
\hline $\operatorname{Srf} 60 \mu \mathrm{M}$ & 8.3 & 23.2 & 13.8 & 15.2 & 39.5 & 100 \\
\hline Srf $240 \mu \mathrm{M}$ & 11.1 & 22.4 & 12.6 & 16.1 & 37.8 & 100 \\
\hline Srf $500 \mu \mathrm{M}$ & 11.4 & 21.7 & 12.5 & 16.2 & 38.2 & 100 \\
\hline Srf $766 \mu \mathrm{M}$ & 12.3 & 21.9 & 12.3 & 16.4 & 37.1 & 100 \\
\hline
\end{tabular}

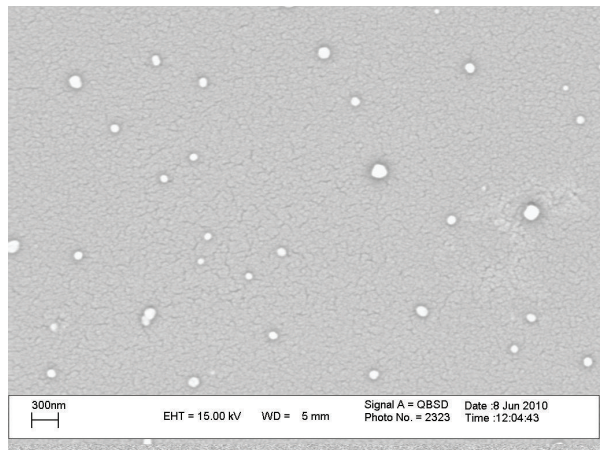

(a)

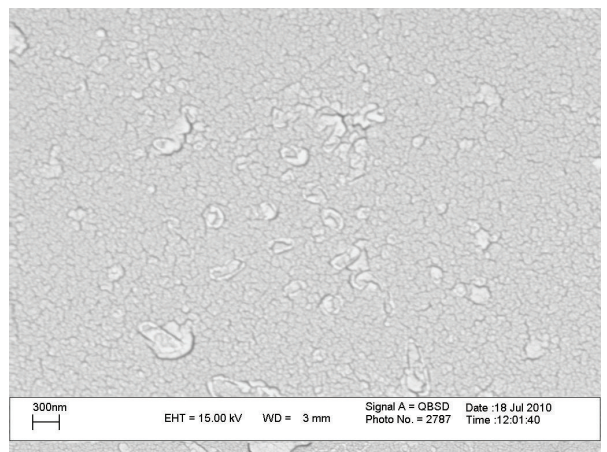

(b)

FIGURE 2: Scanning electron microscope scan of surfactin nanomicelles in distilled water (a) and PBS $(\mathrm{pH}=7.4)(\mathrm{b})$.

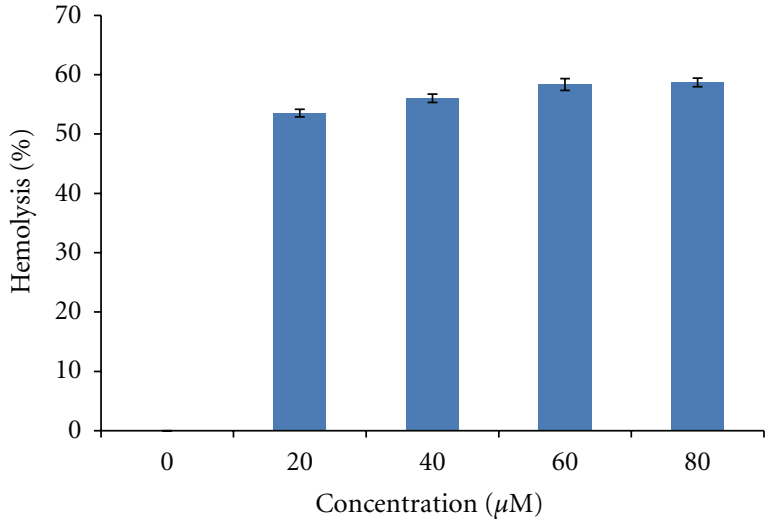

(A)

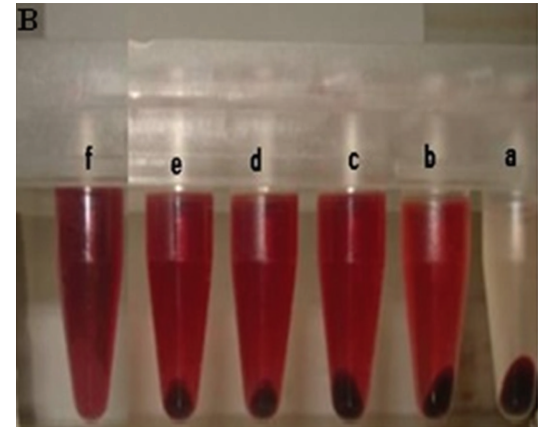

(B)

Figure 3: Surfactin hemolysis assay. (A) $\mathrm{HC}_{50}$ of surfactin $\mathrm{C}-15$ was estimated $47 \mu \mathrm{M}$; (B) the macroscopic figure of surfactin C-15 hemolysis assay in (a) negative control, (b) $20 \mu \mathrm{M}$, (c) $40 \mu \mathrm{M}$, (d) $60 \mu \mathrm{M}$, (e) $80 \mu \mathrm{M}$, and (f) positive control.

concentration of surfactin that bursts $50 \%$ of RBC [10] was $47 \mu \mathrm{M}$.

3.4. MTT Assay. To study the cytotoxic effects of surfactin C-15, HeLa cell line was treated with different concentration of surfactin C-15 for 16, 24, and $48 \mathrm{~h}$, and then cell viability was determined by MTT assay. Surfactin C-15 arrested HeLa cell line growth in a dose- and time-dependent method (Figure 4), with $\mathrm{IC}_{50}$ at 16,24 , and $48 \mathrm{~h}$ of $86.9,73.1$, and $50.2 \mu \mathrm{M}$, respectively.

\section{Discussion and Conclusion}

In this study, scanning electron microscope determined that surfactin C-15 exhibits different manners in different ionic aqueous solutions. Surfactin nanomicelles in PBS show the presence of large and amorphous aggregates. This is a similar result to that observed by Zou et al. [20]. The nanomicelles in distilled water are spherical in shape and smaller in size compared with the nanomicelles in PBA, and this caused different ionic strengths in distilled water and PBS. The study carried out by $\mathrm{Li}$ et al. showed that when the acyl chain length of the surfactin decreases, the hemolytic activity under hypotonic conditions decreases [10], and in this study the $\mathrm{HC}_{50}$ of surfactin $\mathrm{C}-14$ was recorded $300 \mu \mathrm{M}$. According to our study, $\mathrm{HC}_{50}$ of surfactin $\mathrm{C}-15$ is $47 \mu \mathrm{M}$ that is consistent with $\mathrm{Li}$ et al. studies. Surfactins have been considered to be potential antitumoral agents. Recently, it is reported that the cytotoxic effects of surfactins on tumor cells are by inducing the apoptosis, which is related with 


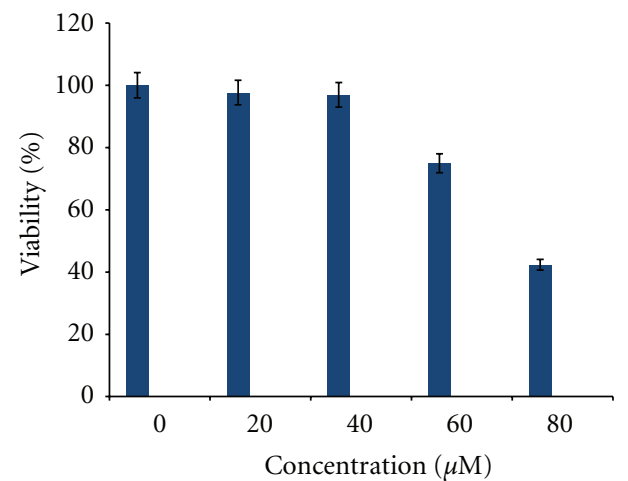

(a)

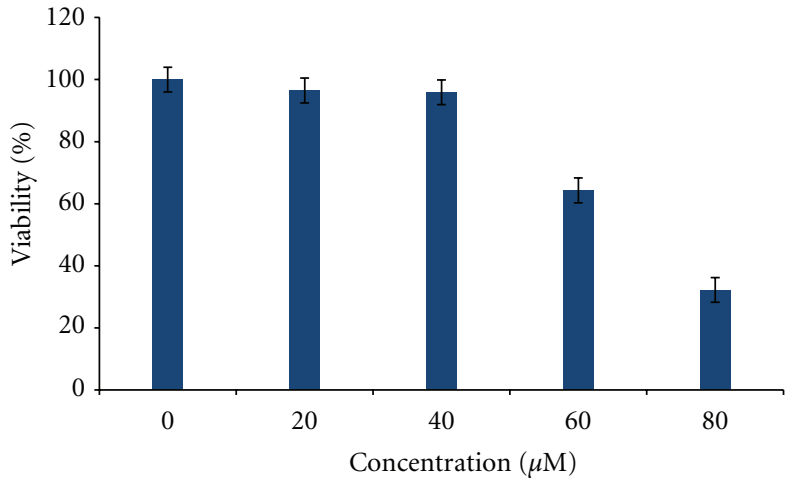

(b)

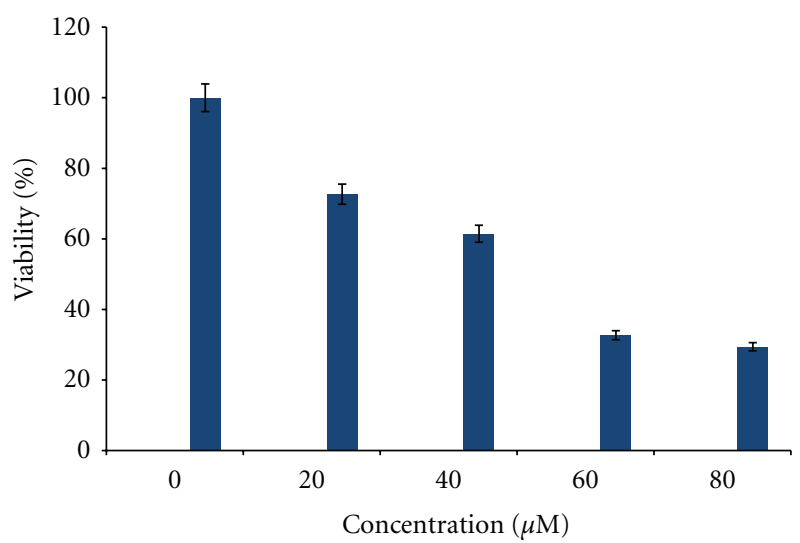

(c)

Figure 4: Cell viability assay for surfactin C-15 on HeLa cell line. The cell line was treated by different concentration of surfactin for (a) $16 \mathrm{~h}$, (b) $24 \mathrm{~h}$, and (c) $48 \mathrm{~h}$ with $\mathrm{IC}_{50}$ of $86.9,73.1$, and $50.2 \mu \mathrm{M}$, respectively.

the enzyme activities. In addition, several biological activities of some lipopeptides are also related with their effects on the enzyme activities. For instance, the selective inhibitory effect of surfactin on cytosolic phospholipase A2 contributes to its anti-inflammatory activities. Another study indicates that the inhibitory effect of surfactin on the alkaline phosphatase had been attributed to a chelating action of the free carboxyl groups of the Asp and Glu residues in the peptide moiety of surfactin [1]. Although the obtained results show the cytotoxic effect of surfactin C-15 on HeLa cell line in a doseand time-dependent method, more studies are necessary to confirm its anticancer effects. Also more studies are needed to determine and clarify the mechanism of surfactin action and anti-proliferative effects on cancerous cell lines targeted delivery.

\section{References}

[1] X. Y. Liu, S. Z. Yang, and B. Z. Mu, "Production and characterization of a C15-surfactin-O-methyl ester by a lipopeptide producing strain Bacillus subtilis HSO121," Process Biochemistry, vol. 44, no. 10, pp. 1144-1151, 2009.

[2] J. Liu, A. Zou, and B. Mu, "Surfactin effect on the physicochemical property of PC liposome," Colloids and Surfaces A, vol. 361, no. 1-3, pp. 90-95, 2010.
[3] H. Kell, J. F. Holzwarth, C. Boettcher, R. K. Heenan, and J. Vater, "Physicochemical studies of the interaction of the lipoheptapeptide surfactin with lipid bilayers of 1- $\alpha$-dimyristoyl phosphatidylcholine," Biophysical Chemistry, vol. 128, no. 2-3, pp. 114-124, 2007.

[4] L. Rodrigues, I. M. Banat, J. Teixeira, and R. Oliveira, "Biosurfactants: potential applications in medicine," Journal of Antimicrobial Chemotherapy, vol. 57, no. 4, pp. 609-618, 2006.

[5] P. Singh and S. S. Cameotra, "Potential applications of microbial surfactants in biomedical sciences," Trends in Biotechnology, vol. 22, no. 3, pp. 142-146, 2004.

[6] S. S. Cameotra and R. S. Makkar, "Recent applications of biosurfactants as biological and immunological molecules," Current Opinion in Microbiology, vol. 7, no. 3, pp. 262-266, 2004.

[7] M. Bortolato, F. Besson, and B. Roux, "Inhibition of alkaline phosphatase by surfactin, a natural chelating lipopeptide from Bacillus subtilis," Biotechnology Letters, vol. 19, no. 5, pp. 433435, 1997.

[8] R. Maget-Dana and M. Ptak, "Interactions of surfactin with membrane models," Biophysical Journal, vol. 68, no. 5, pp. 1937-1943, 1995.

[9] S. Y. Kim, J. Y. Kim, S. H. Kim et al., "Surfactin from Bacillus subtilis displays anti-proliferative effect via apoptosis induction, cell cycle arrest and survival signaling suppression," FEBS Letters, vol. 581, no. 5, pp. 865-871, 2007. 
[10] X. Li, L. Wang, Y. Fan, Q. Feng, and F. Cui, "Biocompatibility and toxicity of nanoparticles and nanotubes," Journal of Nanomaterials, vol. 2012, Article ID 548389, 19 pages, 2012.

[11] J. D. Desai and I. M. Banat, "Microbial production of surfactants and their commercial potential," Microbiology and Molecular Biology Reviews, vol. 61, pp. 47-64, 1997.

[12] X. Li, C. A. van Blitterswijk, Q. Feng, F. Cui, and F. Watari, "The effect of calcium phosphate microstructure on bonerelated cells in vitro," Biomaterials, vol. 29, no. 23, pp. 33063316, 2008.

[13] X. Li, H. Liu, X. Niu et al., "The use of carbo n nanotubes to induce osteogenic differentiation of human adipose-derived MSCs in vitro and ectopic bone formation in vivo," Biomaterials 33, pp. 4818-4827, 2012.

[14] S. K. Smart, A. I. Cassady, G. Q. Lu, and D. J. Martin, "The biocompatibility of carbon nanotubes," Carbon, vol. 44, no. 6 , pp. 1034-1047, 2006.

[15] H. Abbasi, K. A. Noghabi, M. M. Hamedi et al., "Physicochemical characterization of a monorhamnolipid secreted by Pseudomonas aeruginosa MA01 in aqueous media. An experimental and molecular dynamics study," Colloids and Surfaces B, vol. 101, pp. 256-265, 2013.

[16] S. Dufour, M. Deleu, K. Nott, B. Wathelet, P. Thonart, and M. Paquot, "Hemolytic activity of new linear surfactin analogs in relation to their physico-chemical properties," Biochimica et Biophysica Acta, vol. 1726, no. 1, pp. 87-95, 2005.

[17] X. Cao, A. H. Wang, R. Z. Jiao et al., "Surfactin induces apoptosis and G2/M arrest in human breast cancer MCF-7 cells through cell cycle factor regulation," Cell Biochemistry and Biophysics, vol. 55, no. 3, pp. 163-171, 2009.

[18] C. D. Helganson and C. L. Miller, Basic Cell Culture Protocols, vol. 290, Human Press, 2003.

[19] A. Doyle and J. B. Griffiths, Cell and Tissue Culture. Laboratory Procedures in Biotechnology, John Wiley \& Sons, 1998.

[20] A. Zou, J. Liu, V. M. Garamus, Y. Yang, R. Willumeit, and B. $\mathrm{Mu}$, "Micellization activity of the natural lipopeptide [Glui, Asp5] surfactin-C15 in aqueous solution," Journal of Physical Chemistry B, vol. 114, no. 8, pp. 2712-2718, 2010. 

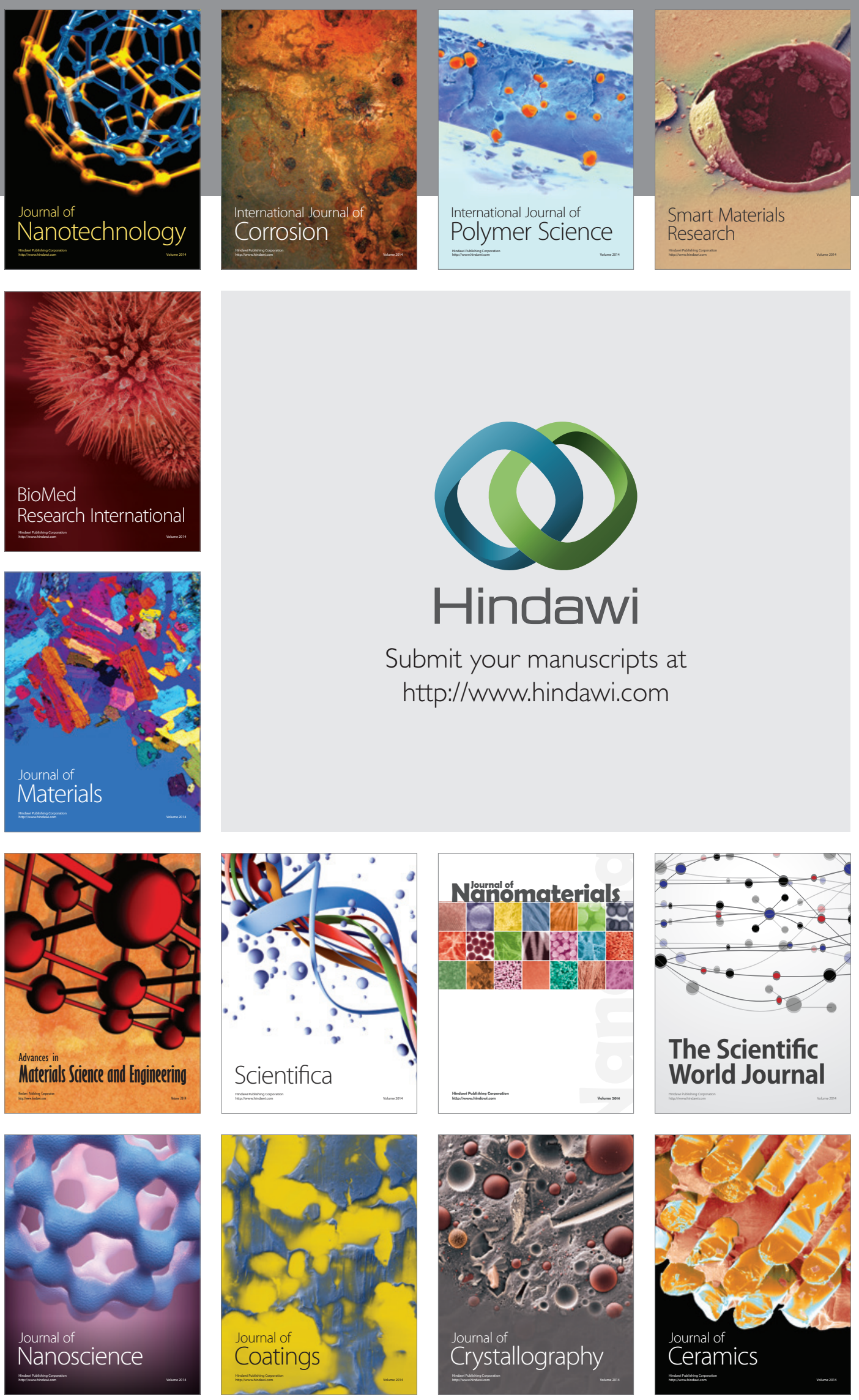

The Scientific World Journal

Submit your manuscripts at

http://www.hindawi.com

\section{World Journal}

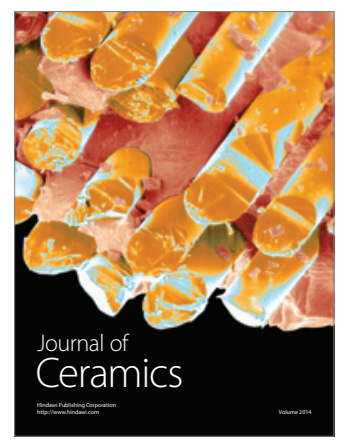

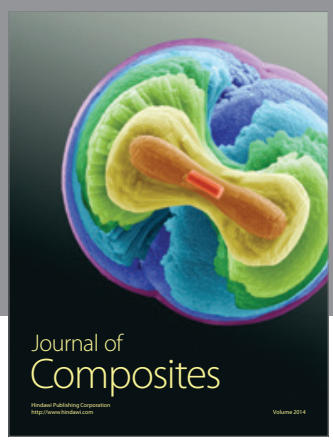
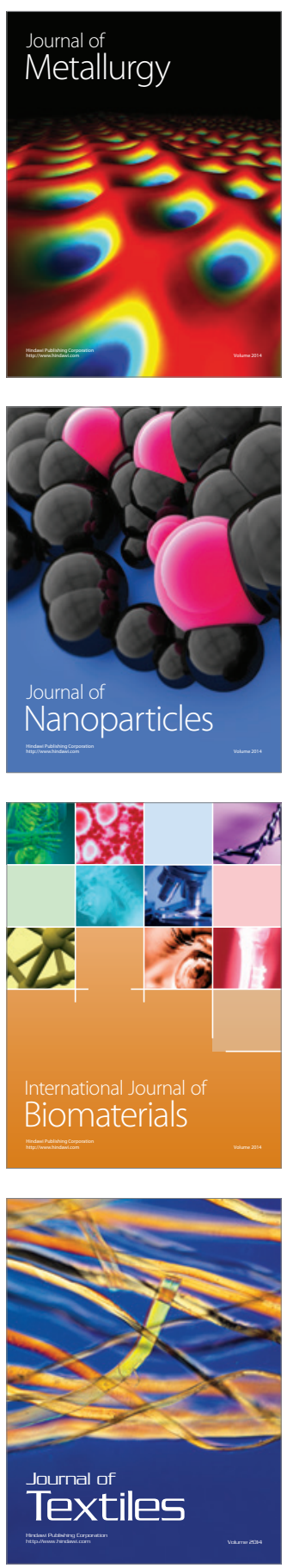